\title{
La educación social en la cultura del bienestar
}

\section{Antoni Petrus}

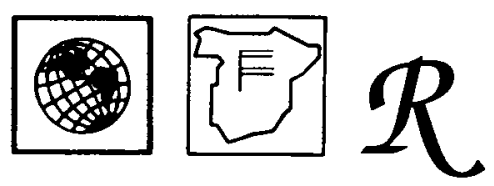

El artículo se inicia presentando los cambios culturales sufridos a partir del Estado del Bienestar y la crisis en la que éste se encuentra, para centrarse posteriormente en las repercusiones que en la educación social ba tenido la cultura del bienestar. El autor analiza los modelos en que actualmente se relaciona la educación social con las formas del Estado del Bienestar asi como los principales enfoques que de la educación social se perciben en la cultura del bienestar.

\section{CAMBIOS CULTURALES Y ESTADO DEL BIENESTAR}

Parece evidente que uno de los cambios sociales más significativos del siglo XX europeo tuvo lugar alrededor de 1950 como consecuencia del industrialismo. Esa «renovada» industrialización trajo consigo una nueva organización social que afectó a casi todos los ámbitos de la vida. La investigación científica, el progreso de las ciencias sociales, el hundimiento de algunos viejos valores y las incertidumbres que el apogeo industrial comportó para la convivencia y las relaciones humanas, fueron algunas de las novedades culturales que se derivaron de la industrialización.

Aunque la reacción ante el nuevo impacto industrial encontró un fuerte rechazo por parte de ciertas filosofías existencialistas y la crítica de algunas posturas sociológicas, lo cierto es que, por primera vez en la historia del hombre, se pensó y se habló de una «sociedad de bienestar». El primer país que experimentó ese «fenómeno social» fue Estados Unidos, pero luego, en la década de los 50, otras naciones de tecnología avanzada se convirtieron también en sociedades ricas y de bienestar. Gran Bretaña y varios países de Europa occidental alcanzaron niveles de bienestar cercanos a los que se habían dado en Estados Unidos pocos años antes. Incluso la Unión Soviética se definió, sin rubor alguno, como una «sociedad de abundancia"

Ante esta apetecible imagen de una «sociedad y cultura del bienestar», la mayoría de gobiernos no regatearon esfuerzo alguno para alcanzar tamaños beneficios. El reto era manifiesto: se trataba de dar el "gran salto" adelante. La consigna transmitida por la mayoría de políticos y legisladores era clara: modernizarse a toda costa. De ahí que a mediados del siglo XX los cambios sociales y económicos fueran casi irreversibles, al tiempo que quedaban soterrados muchos y viejos valores. $Y$ como era de prever, estos cambios en las estructuras y en las formas sociales tuvieron 
sus repercusiones en las orientaciones culturales, siendo una de ellas la creencia de que el cambio era un valor deseable y el progreso un ideal ansiado por todos.

Parece claro que el origen de esa sociedad del bienestar reside, fundamentalmente, en la industrialización, pero es indudable también la existencia de otros factores que favorecieron o posibilitaron la aparición de esta manera de pensar y la adopción de estos nuevos sistemas de organización social. Así, por ejemplo, el proceso de democratización, la secularización de la sociedad, la aparición de ciertos movimientos sociales surgidos precisamente en el ámbito del capitalismo industrial, la construcción de los estados nacionales..., son algunas de las circunstancias que posibilitaron la puesta en marcha de la cultura del bienestar.

Gracias a la reconstrucción política y económica experimentada por algunos países europeos después de la Segunda Guerra Mundial, asistimos por un lado a una consolidación de las formas democráticas, y por otro a la aparición del Estado del Bienestar ( Welfare State). Con esta denominación se significa una forma de gobierno capaz de legitimar una intervención reguladora del crecimiento económico, así como también un intento de redistribución de los recursos sociales de manera más justa.

Aunque es innegable que no todos los análisis y ecografías de la cultura y diseño del Estado del Bienestar son coincidentes, en términos generales podemos convenir en que:

... Por Estado del Bienestar se entiende el conjunto de actuaciones públicas tendentes a garantizar a todo ciudadano de una nación (...) el acceso a un mínimo de servicios que garanticen su supervivencia (entendida en términos sociales y no estrictamente biológicos). (Muñoz de Bustillo, 1989)

En realidad, el Estado de Bienestar es el resultado de una cultura, de un pensamiento. Se trata de un modelo de Estado que, después de haber alcanzado cotas satisfactorias de bienestar económico, decide intervenir en la vida de los ciudadanos con el objetivo de posibilitar su bienestar social y facilitar una mayor calidad de vida de todos ellos. A lo largo del proceso de configuración del Estado del Bienestar, se observa cómo éste va absorbiendo, poco a poco, espacios de economía privada, luego asume parcelas sociales como educación, sanidad y vivienda, para convertirse, por último, en el principal «empresario» del país, lo que le permite intervenir, a manera de juez, en la mayoría de los conflictos que pudieran darse en el seno de una colectividad o nación. En resumen, el Welfare State se define, entre otras, por las siguientes características:

a) Un considerable crecimiento económico- industrial.

b) Decisiva intervención del estado en la orientación y desarrollo de la economía.

c) Notable intervencionismo del poder público en la vida social.

d) Importante aumento del gasto público derivado de los servicios y prestaciones sociales que asume.

e) Importancia del estado como «consumidor».

En el contexto de esta «cultura del bienestar» algunos estados adoptaron un tipo de intervención o gestión social destinada a la producción de bienes y servicios que no eran rentables para el sector privado. A partir de la teoría general del bienestar - fundamentada en la llamada economía del bienestar- son extraídas una serie de implicaciones que remarcan la posibilidad de que el estado garantice a todos los ciudadanos un nivel mínimo de servicios públicos, asistenciales y de previsión social. Esta «filosofía» económica, defendida por Keynes y plasmada en Gran Bretaña por el laboralista William Henry Beveridge, supuso, además de un nuevo modelo de prestación social, una posibilidad de regular el mercado y la cultura delconsumo.

Cabe señalar también que la filosofía económica en la que se iba a sustentar el Estado del Bienestar insistía en que los gastos públicos derivados de la consecución de esta prestación de servicios por parte del estado, se tenían que obrener por imposición directa progresiva- ya fuera personal o empresarial- ya que éste era el único 
camino para obtener una verdadera redistribución de bienes, objetivo prioritario de la cultura del bienestar.

Aunque desde una perspectiva economicista no siempre los acuerdos fueron consensuados y totales, lo cierto es que hubo importantes afinidades acerca de las estrategias a adoptar frente a los problemas sociales y políticos. Partidos predominantes en la política europea de postguerra como los liberales, conservadores democristianos y socialistas llegaron a fáciles acuerdos respecto a los derechos y problemas ciudadanos a proteger desde la gestión democrática (seguridad social, educación vivienda, paro...). En sentido estricto, estos acuerdos fueron de fácil consenso porque el Estado del Bienestar buscaba un orden social que, basado en la democracia, diera una nueva entidad a lo público y lo privado como fundamento de sus tres grandes objetivos: seguridad social, libertad e igualdad de todos los ciudadanos. (1)

Desde una perspectiva teórica, los partidos políticos responsables de la gestión pública en los países europeos más industrializados de los años 1950-70, coincidían en afirmar que el Welfare State era el mejor modelo, quizás el único, para alcanzar un correcto funcionamiento del sistema social. Esta opinión se fundamentaba en la creencia de que para alcanzar una fase más avanzada y superior de desarrollo de la ciudadanía era preciso redistribuir la riqueza para obtener así una mayor igualdad social (Zapatero, 1989).

\section{CULTURA DEL BIENESTAR Y ESTADO DEL BIENESTAR}

Antes de adentrarnos en el análisis de las relaciones entre cultura del bienestar y educación social, es preciso preguntarse si la sociedad del bienestar pasa forzosamente por esa «inseparable relación», por ese inevitable binomio tantas veces comentado de bienestar-estado. De la respuesta que se dé a esta pregunta se derivará otro interrogante no menos importante: ¿El bienestar sólo puede alcanzarse a través del estado?

Un análisis preciso del proceso histórico seguido en el advenimiento del Estado del Bienestar, nos demuestra que la cultura del bienestar europeo va unida al crecimiento de la burguesía en todas sus variadas formas. $Y$ en cierta manera es lógico que así sea , ya que la cultura del bienestar no es otra cosa que desear y ver satisfechas un conjunto de necesidades que van más allá de la biológica exigencia de alimentarse, vestirse y cobijarse.

La cultura del bienestar implica que la sociedad tenga plenamente satisfechas estas tres necesidades elementales y que, una vez logrado ese primer objetivo pueda asumir el reto de ver cumplidas otras urgencias sociales no menos importantes. Ahora bien, para que podamos referirnos con precisión a la situación de «bienestante» fue preciso convenir, previamente, que la libertad y la igualdad eran derechos inherentes a toda persona, de donde se desprende que la cultura del bienestar es un concepto ligado a los principios filosóficos y culturales del siglo XVIII. Con ello queremos hacer ver que para la implantación de la cultura del bienestar es necesario que la sociedad sea libre y que en ella exista ya un amplio sector de ciudadanos que gozan de ese privilegiada situación de bienestar cultural y social.

En cierta manera fue la propia sociedad europea de los años 50 la que en su momento pensó que el estado era el mejor garante de esa universalización del bienestar. Los poderes públicos asumieron esa responsabilidad y fueron los encargados de intentar extender la situación de privilegio del bienestar a todos los demás sectores de la población. El estado se convirtió así en el necesario instrumento para universalizar el bienestar a la sociedad en su conjunto, lo cual supone también otorgarle al la responsabilidad de especificar y determinar lo que en cada situación se entiende por bienestar. Y ello es una pesada responsabilidad, ya que el concepto de bienestar no es universal- como no lo es casi ningún concepto social-. 
El concepto y la valoración de lo que se entiende por «bienestar» depende de situaciones concretas y es competencia, pensamos, de la sociedad en su conjunto, no sólo del estado. El ciudadano tiene una doble obligación frente al diseño de la cultura del bienestar. Por un lado debe elegir su propio bienestar y no permitir que la intervención del estado vaya más allá de las parcelas que su personal libertad le otorgan; y por otro es preciso que el ciudadano comprenda y asuma que no todo problema o dificultad social y cultural puede y debe ser solucionado por el estado.

\section{CRISIS... DE LEGITIMIZACION DEL ESTADO DEL BIENESTAR}

La historia nos demuestra que casi siempre que un estado asume un fuerte protagonismo en el diseño y responsabilidad de la vida de los ciudadanos, corre el riesgo de que cuando los umbrales de insatisfacción de la población son de suficiente entidad, se le responsabilice de las contradicciones entre sus demandas y la esperada satisfacción de ellas.

Al margen de la mayor o menor validez de la anterior afirmación, es indudable que al hacer mención del Estado del Bienestar aparece alguna referencia a las dificultades del modelo, a las dudas que el mismo genera y la situación de crisis en que se encuentra. De ahí que textos como el siguientes sean habituales:

« Hoy vemos que en muchas sociedades capitalistas esta fórmula de paz (el Estado del Bienestar) es objeto de dudas, crítica fundamental y conflicto político. Parece que el más ampliamente aceptado instrumento de resolución de problemas políticos ha venido a hacerse problemático, y que, en todo caso, la incuestionable confianza en el Estado del Bienestar y su expansión futura se ha evaporado rápidamente» (López Hidalgo, 1992)

Hacer un diagnóstico de la crisis del Estado del Bienestar no es sencillo. Y no lo es porque a pesar de la abundancia de análisis e interpretaciones de las causas que motivaron el cuestionarse, e incluso invalidar, las estrategias políticas de la sociedad del bienestar, lo cierto es que las conclusiones derivadas de estos análisis no son coincidentes. Es más, en algunos casos los argumentos parecen incluso contradictorios.

Con todo, la realidad es que en la década de los 70 la política social representativa del Welfare State se tambalea y se ve sometida a duras críticas. Señalemos a continuación algunas de las circunstancias que, desde nuestro personal punto de vista, influyeron de manera más decisiva en esa crítica al Estado del Bienestar y tuvieron una mayor repercusión en el campo de la educación social.

- Aumento de necesidades sociales y disminución de los recursos disponibles para satisfacerlas.

- Problemas para conseguir el pleno empleo y el crecimiento económico continuado.

- Al faltar el pleno empleo aumentan, asimismo, las demandas de protección social.

- Aumenta el paro y la cronificación del mismo, lo que genera una demanda adicional de prestaciones que no son satisfechas por ningún tipo de seguro social.

- Aparecen viejas necesidades sociales que se suponían definitivamente superadas.

- Se cuestiona quiénes han sido los auténticos beneficiados de las prestaciones sociales, argumentándose que las clases medias han recibido muchas de estas prestaciones.

- Aumentan los presupuestos estatales, con el consiguiente esfuerzo fiscal que ello supone para parte de los ciudadanos y las empresas.

Un análisis riguroso de la crisis y de la legitimización del Estado del Bienestar debe pasar, forzosamente, por tres tipos de consideraciones: las de carácter económi- 
co, las de típo político y las de entidad ideológicas. Sólo así se podrá tener una idea aproximada del complejo fenómeno que se encierra detrás de la expresión crisis del Estado el Bienestar.

Desde esta perspectiva, resulta de máximo interés reflexionar acerca de si, cómo dicen algunos autores, la crisis del Estado del Bienestar ha generado dos tipos de población: los integrados y los excluidos. Otros van más lejos incluso en sus interpretaciones y no dudan en afirmar que esta forma de organización social es una estrategia

«... para sobrevivir y oponerse a la alternativa que representa el Estado socialista, reflejando las transformaciones experimentadas por el Estado contemporáneo con respecto al primitivo Estado liberal de Derecho" (Alvarez Conde, 1985)

Claus Offe rechaza la idea convencional del Estado del Bienestar como proveedor de prestaciones sociales, interpretando que actúa como una institución política y administrativa cuyo principal objetivo reside en dominar y manejar las estructuras de la socialización de los ciudadanos y la economía capitalista. Para este autor, las ciencias sociales tienen una importante responsabilidad frente al problema del Estado del Bienestar, y solicita de ellas que abandonen su afán de convertirse en consejeras de los administradores y de los responsables de la política para orientar su trabajo a:

«... promover debates sobre tendencias de crisis, y por tanto, a identificar deliberadamente más problemas de los que pueden asimilar y resolver las élites dominantes en política, administración y finanzas» (Offe, 1994)

Al margen de estos u otros planteamientos, existe una realidad incuestionable: la crisis y las contradicciones del Estado del Bienestar son tema de debate, como lo son también algunos de sus principios legitimadores y las vías alternativas que a esta sociedad del bienestar se están proponiendo.

\section{EDUCACION SOCIAL Y MODELOS DEL BIENESTAR}

Después de la consolidación y posterior crisis del Estado del Bienestar, se ha producido un rico debate en torno a cuál es la realidad presente y qué futuro espera a la actual forma de Welfare State. Debate que, por supuesto, está en la base del presente y futuro de la misma educación social.

En cierta manera, las relaciones entre la cultura del bienestar y la educación social son herencia de las formas que los liberales, conservadores democristianos y socialistas adoptaron en su día, dando lugar a los modelos de organización política predominantes en Europa. En la.actualidad podemos referirnos a tres maneras o modelos, claramente diferenciados, de relacionar la educación social con las actuales formas de Estado del Bienestar: modelo liberal-demócrata, modelo social-demócrata y modelo neocorporativista.

\section{Modelo liberal-demócrata.}

La forma, espacio y presencia de la educación social en nuestra sociedad depende, principalmente, de la concepción que se tenga del Estado, de la sociedad y de la misma educación social. Para el modelo liberal-demócrata, por ejemplo, el Estado es una institución política neutral, y en cierta manera ajena a las fuerzas sociales y económicas, que actúan con un relativo margen de libertad. El Estado adopta una función más cercana al arbitraje que al protagonismo. De ahí que procure intervenir sólo cuando los diferentes intereses de los partidos políticos, agrupaciones empresariales y sindicales, sectores sociales, etc., entran en conflicto. 
En una sociedad democrática y competitiva, las diferentes fuerzas sociales son las encargadas de defender sus propios espacios y opciones, reservándose el Estado la función de propiciar las condiciones de igualdad y justicia. Sin embargo, el Estado tiene una función que va más allá del mero neutralismo: puede asumir una acción compensadora e intervenir cuando las circunstancias dan lugar a problemas que inciden en la justicia y en la estructura misma de lo social. Dicho en otros términos: el Estado tiene la responsabilidad de mantener y asegurar la llamada paz social. Sin embargo, las contradiciones del sistema obligan, en ocasiones, a que el Estado tenga que intervenir tanto en lo económico como en lo social, asegurando así que los sectores de población menos favorecidos obtengan también los beneficios de un Estado social y de Derecho. Esto justifica que también en el modelo liberal-demócrata la educación social sea competencia y responsabilidad, en alguna medida, del Estado.

\section{Modelo social-demócrata.}

Aunque no podamos referirnos a este modelo como un todo unitario y único, lo cierto es que los estados socialdemócratas apuestan abiertamente por la forma de Welfare State, insistiendo de manera precisa en la necesidad de que las políticas de Estado deben asegurar y hacer posible la redistribución de los beneficios de la convivencia social. Es evidente que esta clara defensa del Estado como avalador del bienestar comporta el tener que adoptar, en ocasiones, medidas de control y asumir los fuertes dispendios que una generalización de los servicios sociales comporta ( con el consiguiente y casi siempre progresivo aumento de la presión fiscal sobre las empresas y los ciudadanos «bienestantes»).

En el ámbito de este modelo encontramos autores que entienden que la consecución del Estado del Bienestar no es sólo el reflejo o fruto del crecimiento económico, sino también el resultado de las reivindicaciones de los obreros y de los mismos esquemas políticos. En este modelo, la educación social es considerada como un importante factor de igualdad entre todos los ciudadanos y competencia del Estado. (2).

\section{Modelo neocorporativista.}

Este modelo surge como alternativa a las limitaciones que supone un bienestar fundamentado en la competitividad económica y en los planteamientos políticos basados en las "clásicas» luchas de clase. A pesar de no representar un modelo único y consensuado, lo cierto es que en términos generales se presenta como un complemento a la tradicional forma de representación monopolizada por los partidos políticos. Con todo, hay autores que ven e en este modelo una nueva forma de control y de legitimización de las políticas económicas de los Estados.

El modelo neocorporativista defiende un mayor grado de participación ciudadana en las organizaciones de gobierno de los estados a través de nuevas formas de agrupaciones (cámaras, federaciones sindicales, consejos de difente entidad, etc.). Aunque el corporativismo es un fenómeno que tuvo especial importancia a finales de los años 70 y principios de los 80 , estamos convencidos que sea cual fuere la fórmula que adopten estas agrupaciones, el corporativismo es un fenómeno de importantes repercusiones para la educación social y algo a tener muy en cuenta si no queremos que la legitimidad y el futuro de la cultura del bienestar pase a ser un mero nominalismo histórico.

\section{CULTURA DEL BIENESTAR Y SUS REPERCUSIONES EN LA EDUCACION SOCIAL}

Una de las más importantes consecuencias de la implantación del Welfare State ha sido la paulatina aplicación del principio de igualdad entre los ciudadanos, 
lo que ha permitido suprimir muchas de las trabas y viejos privilegios que impedían alcanzar una auténtica cultura del bienestar.

A partir de la aplicación de este primer principio, la cultura del bienestar ha posibilitado que la mayoría de ciudadanos hayan entendido cuáles son sus derechos y libertades por el hecho de vivir en un Estado Social y de Derecho. Fruto de este contínuo proceso de adquisición de conciencia social ha sido, asimismo, el solicitar el cumplimiento del compromiso que constitucionalmente tienen estos Estados para que la generalización y eficacia de estos derechos sea una realidad y no un mero redactado en el máximo ordenamiento jurídico de su país. En otras palabras, los ciudadanos han comprendido que la generalización del bienestar es un derecho.

Las constituciones que regulan la vida de los ciudadanos en los países del bienestar son todo un alegato en favor de la educación social como un derecho más dentro de esa cultura del bienestar. Al margen de los análisis más o menos correctos que seamos capaces de elaborar, lo cierto es que nuestra Constitución, haciéndose eco del enfoque más tradicional de la educación social, explicita cuáles son sus principales ámbitos de intervención.

Marginación, delincuencia, instituciones penitenciarias, educación de adultos, tercera edad, servicios sociales, tiempo libre, animación sociocultural, etc... quedan así contemplados en nuestro máximo ordenamiento jurídico, posiblemente como reflejo de una problemática y una demanda social existente. Este enfoque «constitucional" ha posibilitado que todavía hoy la educación social tenga una función intervencionista más frecuente sobre la realidad social descompensada o desajustada, entendiéndose en ocasiones como instrumento compensador o de mejora de los sectores menos privilegiados de la sociedad.

Un análisis detenido de lo que sucede en nuestra cultura del bienestar, permite afirmar que nos encontramos en pleno reajuste de algunas de las funciones del estado y también de otras instituciones como la familia o la empresa. De hecho se repite el mismo fenómeno que se dio con ocasión del advenimiento de la revolución industrial. Es posible incluso, como se afirma en El Libro Verde de la Política Social Europea, que estemos en plena fase de:

«... revaluación del papel del Estado de bienestar, no sólo debido a las presiones financieras sino, más fundamentalmente, a la necesidad de avanzar hacia la adopción de unas políticas más activas dirigidas a garantizar la integración de las personas en el trabajo y en la sociedad» (Comisión de las Comunidades Europeas, 1993)

Sea como fuere, lo cierto es que la cultura del bienestar es un importante logro de las sociedades modernas al que los ciudadanos no están dispuestos ya a renunciar. La protección social y los nuevos ámbitos de la educación social son espacios de unánime apoyo y dos factores de fuerte impacto en la lucha por la cohesión social. Sin embargo, no se escapa al observador que a pesar de su importancia como factor de cohesión y de solidaridad social, el bienestar y la educación social se enfrentan con problemas que dificultan su pleno ejercio.

El aumento del desempleo, el envejecimiento de la población, los cambios en las estructuras familiares, la creciente pobreza, el fenómeno de la exclusión social, la masiva demanda de prestaciones sociales, etc., son algunos de los principales obstáculos que la generalización de la protección y la educación social tienen en nuestros días. Si a ello añadimos el necesario control del gasto público y la aplicación de la llamada estrategia de la «selección del objetivo» que comporta orientar el gasto público a la solución de los problemas en los sectores más necesitados, se tendrá una radiografía de los principales males que aquejan nuestra actual sociedad del bienestar (con las consiguientes repercusiones que ello comporta para el desarrollo de la educación social).

Una mirada a la historia de la educación social es suficiente para demostrar que sus fases de máximo apogeo coinciden con las situaciones más conflictivas de la sociedad. De ahí, pues, que en un momento como el actual, con un mercado de trabajo flexible y serios problemas de pobreza, marginación y exclusión social, en una 
sociedad que tiende a alejar parte de la población de las oportunidades económicas y educativas, las demandas de prestaciones sociales y educativas sean cada vez mayores.

El impacto del cambio industrial sobre los trabajadores con niveles bajos de formación, las nuevas formas de inmigración ilegal y los constantes movimientos de población hacia los países de la cultura del bienestar, obligan a una seria reflexión acerca del papel que la educación social debe jugar frente al riesgo de la aparición de nuevas formas de exclusión social. Estamos convencidos que sólo una creativa e innovadora estrategia de protección y educación social podrá evitar el riesgo de tener que convivir con situaciones injustas y conducentes a lógicas actitudes violentas o desviadas por parte de la población más vulnerable, que se ve privada del derecho de formar parte de esa sociedad y cultura del bienestar a la que tiene derecho.

Aunque no negamos y concedamos a la educación - escolar y social- la importancia que todos sabemos que tiene, creemos que las actuales formas de cultura del bienestar obligan a introducir nuevas perspectivas en el discurso pedagógico social. Pensemos, por ejemplo, en los jóvenes que salen de nuestas escuelas. La mayoría de ellos no pueden ser considerados como un producto acabado, sino más bien como un potencial de desarrollo que precisará de nuevas intervenciones educativas. La educación social la entendemos hoy como una segunda o tercera oportunidad para muchos de los ciudadanos.

Otra reflexión que aflora tan pronto se analiza la función de la educación social en el ámbito de la actual sociedad del bienestar, es la necesidad de que las políticas sociales consideren los problemas en su totalidad. Cualquier planteamiento social que no considere la población en general (hombres y mujeres, campo y ciudad, jóvenes y ancianos, ricos y pobres, excluidos e integrados, blancos y negros, iguales y diferentes...) está condenada, a la larga, al fracaso. De ahí el peligro de reducir la educación social a una mera acción sobre la realidad que es. En una sociedad en cambio como la nuestra, es competencia también de la educación social considerar y reflexionar acerca de la realidad que no es pero que debe ser.

En varias ocasiones hemos afirmado que el Estado de Bienestar debe intentar dar cobertura a la totalidad de la población. Sin renunciar a este justo propósito, lo cierto es que en las actuales condiciones sociales parece oportuno considerar también nuevas fórmulas y ver si éstas permiten alcanzar mejores resultados a partir de una colaboración entre lo público y lo privado. Aunque la prestación social puede - y debe - ser responsabilidad de la esfera pública y de lo privado, en ningún caso, pensamos, es conveniente dejar de reconocer al Estado el derecho y la necesidad de que regule el sistema general de la oferta social. Esta consideración es válida, asimismo, para la educación social, que si bien tendrá en lo público su máximo exponente y responsabilidad, hay campos de la pedagogía social que pueden ser asumidos por el sector privado.

Otra característica de la educación social en nuestra cultura del bienestar es el hecho de que su planificación y la toma de decisiones no pueden tener el carácter local de antaño. Con ello no queremos decir que la educación social deje de aplicar el principio de adecuación a la realidad. Al contrario, si la realidad está fraccionada y es cambiante, ello nos condiciona, más si cabe, a tenerla como primer referente de nuestra actuación como educadores. Lo que pretendemos señalar es que las políticas sociales son cada vez más generales y de mayor ámbito de aplicación. De hecho, al ser Europa el referente de nuestra cultura del bienestar, se impone lo que se ha dado en llamar convergencia de las políticas sociales. Esta circunstancia tiene también sus repercusiones en la educación social, que se ve obligada a actuar teniendo presente los referentes que se dan en Europa. Con ello no pretendemos defender una armonización de la educación social, sino reflexionar acerca de la existencia de un marco que rentabilice los distintos esfuerzos en el contexto europeo. La libre circulación de personas y el mercado único pueden ser dos valiosos argumentos para justificar la importancia del tema. Como es habitual afirmar en los foros de la UE, «Los sistemas nacionales, convergerán y al mismo tiempo seguirán siendo autónomos» (Comisión de las Comunidades Europeas, 1993). 
La existencia de problemas de tanta importancia como el derecho de residencia y la prohibición de cualquier discriminación por razón de la nacionalidad, son dos buenos ejemplos de cómo la educación social se ve obligada a introducir constantes cambios en sus principios y diseños para poder atender a las condiciones derivadas de la cultura y el Estado del Bienestar en sus formas y realidades actuales.

Pasemos a continuación a comentar cuáles son las principales formas que adopta, en nuestro contexto cultural y económico, la educación social.

\section{CULTURA DEL BIENESTAR Y ENFOQUES DE LA EDUCACION SOCIAL}

La educación social es hoy un concepto de difícil definición, en parte porque su conceptualización tiende a variar según la ideología, la filosofía,... y la visión de sociedad del bienestar desde la que se contemple. Somos conscientes, también, que la educación social realizada y pensada en nuestro país está, todavía, íntimamente ligada a una función benéfica, a una función de ayuda educativa a personas o grupos que configuran la realidad social menos favorecida. Y nuestra Constitución indica cuáles son los principales ámbitos de lo que nosotros denominamos educación social.

Sin embargo, además de esa primera y todavía prioritaria visión «marginal» y «constitucional» de la educación social, hay otros campos de acción o intervención que le competen. Hagamos, pues, una rápida mención de los principales enfoques que de la educación social percibimos en nuestra cultura del bienestar.

\section{Educación social como socialización}

En amplios sectores de nuestra sociedad la educación social es concebida como sinónimo de correcta socialización, ya sea "socialización primaria, secundaria o terciaria». Es decir, la educación social es el largo proceso gracias al cual un individuo biológico es transformado en individuo social, transformación que se consigue a través de la transmisión y aprendizaje de la cultura de la sociedad. Gracias a ese proceso de socialización, el individuo adquiriere las capacidades de participación e integración social en el grupo que le corresponde vivir. La socialización se entiende, pues, como un proceso de extensión del yo y como una constante inserción del individuo en la vida del grupo.

Es importante observar que esa integración social es el objetivo prioritario de las políticas sociales derivadas del Estado del Bienestar. La educación social es entendida, en este contexto, como el complejo mecanismo gracias al cual un individuo asume los valores, las normas y los comportamientos del grupo al que desea, o se desea, integrarlo. Desde esta perspectiva, la educación social consistirá en un aprendizaje social o en una absorción del individuo por parte de la sociedad, ya sea a través de la enculturación o aculturación.

Aunque la educación social no renuncia a la socialización primaria ni a la socialización secundaria, lo cierto es que tiene en la socialización terciaria (la llamada «resocialización», «reeducación social», «educación correccional», etc.,) su principal campo de intervención educativa. Con la educación social un individuo se reincorpora a la sociedad después de haber evidenciado conductas antisociales, conductas asociales o disociales. La socialización terciaria sería, pues, el proceso de «resocialización por el cual un hombre dis-socializado se convierte en socializado.» (3)

\section{Educación social como acción social cualificada}

A partir de la aplicación de las políticas de eficacia y calidad tan próximas al Estado del Bienestar, la educación social es concebida también como una interven- 
ción cualificada de unos profesionales, con la ayuda de unos recursos y la presencia de unas determinadas circunstancias sobre un sistema social . El fin de esta intervención será que coadyuve o venga a poner remedio a ciertas necesidades humanas generadas por el desigual aprovechamiento de los beneficios de la convivencia humana.

Las situaciones de injusticia social y el desequilibrio generado por la crisis de la cultura del bienestar, así como el rápido proceso de tecnificación y la fragmentación de la conciencia colectiva, han obligado a las políticas sociales a tomar conciencia de la dificultad y buscar soluciones eficaces para los problemas que surgen en la frontera de la denominada normal y anormal adaptación social. Y una de estas soluciones es la educación social.

La educación social sería, en este sentido, una acción consciente, reflexiva y planificada, fundamentada en la técnica y la metodología, a fin de incidir positivamente sobre una realidad social marginal determinada. Desde este análisis la educación social es, según Lowy, «una acción profesional (cualificada) sobre un sistema social derivada de un diagnóstico social y a través de medios adecuados y destinados al cambio» (4).

\section{Educación social: factor de intervención educativa cerca de la inadaptación social}

Aunque el concepto de inadaptación social resulta falto de concreción, algunos autores hacen uso de la expresión educación social para referirse exclusivamente a la intervención educativa cerca de la inadaptación social. Si bien las reminiscencias de esta manera de entender la educación social son evidentes y poco adecuadas a sus actuales enfoques, lo cierto es que la educación social tiene, entre sus cometidos, dar solución a las distintas circunstancias de inadaptación y marginación social que se puedan dar en una determinada sociedad.

Este enfoque de la educación social nos parece poco vigente y nada adecuado a la actual realidad de la cultura del bienestar. Además de solucionar determinados problemas de convivencia, la educación social tiene dos cometidos no menos importantes: el primero, desarrollar y promover la calidad de vida de todos los ciudadanos; el segundo aplicar estrategias de "prevención de causas». En este sentido, como dice Colom la educación social sería "un instrumento igualitario, compensador, de mejora de la vida social y personal»

\section{Educación social como adquisición de competencias sociales.}

Nunca como en la actualidad se ha dado tanta importancia al fenómeno de la integración social, ya que el Estado del Bienestar descansa en una irrenunciable premisa: debe evitarse todo tipo de conflicto que pueda romper la armonía de la convivencia. Desde esta perspectiva, la educación social es concebida como la adquisición de competencias sociales, es decir como la acción conducente al logro o al aprendizaje de aquellas virtudes o capacidades sociales que un grupo o sociedad considera correctas para alcanzar el éxito social. La educación social es un eficaz camino para alcanzar esa anhelada paz social que se fundamenta, a su vez, en la integración de todos sus miembros.

Para que podamos hablar de competencia social se han de dar dos condiciones: primero, que el sujeto tenga éxito en el cumplimiento de las expectativas sociales que sobre él recaigan; y segundo, que el sujeto sea consciente de su progreso personal como ser humano, lo cual implica un cierto grado de satisfacción en su actuación personal. En este sentido es palpable que el sujeto de la «educación social» no puede ser un agente pasivo frente a los estímulos, sino que, por el contratio, debe actuar y ser un agente activo ante las circunstancias de su propio desarrollo. 
Para la educación social inmersa en la sociedad del bienestar es fundamental la formación y adquisición de babilidades sociales o competencias para la vida en el grupo. La educación social busca educar para la participación social, para beneficiarse de los beneficios de la cultura del bienestar, lo cual supone incidir en las estructuras cognitivas y afectivas del sujeto y trabajar a efectos de producir un cambio en su repertorio conductual. No olvidemos, no obstante, que para el logro de una competencia social, en muchos casos, es imprescindible introducir pequeños cambios dentro de la familia, así como también en las relaciones con los compañeros de edad, con los adultos y en el ámbito de las relaciones laborales, lo cual supone todo un reto más para el Estado del Bienestar. (Garrido Genovés, 1989)

\section{Educación social como didáctica social}

A partir de la década de los años setenta, como consecuencia del principio de competitividad y eficacia que identifica muchas de las actuaciones del Estado del Bienestar, la educación social es entendida como un conjunto de estrategias e intervenciones socio-comunitarias en el medio social- marginal o no-. En este sentido, la educación social es una intervención sociocomunitaria, es algo así como una didáctica social.

Este enfoque de la educación social está muy próximo a lo que podríamos denominar paradigma tecnológico de la educación, y responde a una convincente manera de entender la educación social, que siempre tendrá la acción y la mejora de las situaciones sociales como referencia de su intervención. Sólo este enfoque praxiológico, afirman algunos, evitará que la educación social pase a ser un saber axiológico dentro del amplio abanico de conocimientos pedagógicos.

\section{Educación social y formación política del ciudadano}

Aunque concebir la educación social como formación social y política del ciudadano parece estar muy lejos de la filosofía en la que se ampara la sociedad del bienestar, lo cierto es que esta postura ha tenido importante predicamento en otras épocas de la historia. No ignoremos, por otro lado, que la educación política forma parte de la educación en su sentido más amplio, y en consecuencia está fuertemente ligada a la educación social. Si política es la disciplina o ciencia que nos dice lo que hay que regularizar aquí y ahora para poder disponer de un modelo de convivencia, si la «educación política", como decía Mhaiki, da significado a todas las demás materias, no cabe duda de la relativa proximidad entre los conceptos de «política» $y$ «educación social», máxime en nuestra sociedad de fuerte presencia estatal (5).

\section{Educación social, prevención y control social}

Como hemos visto, en algunos modelos de Estado del Bienestar está conscientemente asumido que todo proceso educativo va emparejado a una cierta acción de control, que según los casos podrá tomar la forma de un control social, moral o cultural.

Desde que T. Parsons concibió el control como prevención de tendencias desviadas, es frecuente definir la educación social como el proceso mediante el cual las tendencias desviadas pueden ser contrarrestadas, operándose así el deseado equilibrio adaptativo y la integración social de los ciudadanos más alejados de las normas sociales. Desde este enfoque, la educación social ejercitaría la función de prevenir la desviación social. Sería como un «forestalling», así como también un control de esa misma desviación en el caso de que se hubiese producido. Desde este enfoque, la educación social supondrá un conjunto de procedimientos utilizados por las sociedades del bienestar a fin 
de que todos sus miembros observen aquellas normas de conducta consensuadas y catalogadas como necesarias para conseguir el orden social. La educación social será la influencia intencional y optimizadora ejercida sobre los ciudadanos o sobre la realidad social, a fin de que individuos o grupos se comporten de distinta forma a como lo bubieren becho de no mediar esa acción educativa y de control.

Haciendo nuestra la "teoría conflictiva», pensamos que la educación social encuentra su espacio en cada uno de los tres factores justificativos de las desigualdades sociales citados por Dahrendorf: poder, normas y funciones sociales. De donde se desprende que la educación social pueda servir, en nuestro Estado del Bienestar, «para ejercer un mayor control social» (Petrus, 1988)

\section{Educación social: trabajo social educativo}

Desde que la intervención social se diseña como una actividad interdisciplinar, es frecuente definir la educación social como trabajo social, o bien que su acción tenga las características propias de un trabajo social. Obviamente este trabjo es entendido, programado y realizado desde la perspectiva educativa y no meramente asistencialista. Es precisamente ese compromiso educativo el que dará una nueva dimensión al trabajo social, convirtiéndolo así en una actividad más comprometida con el cambio de la realidad social injusta.

En una sociedad del bienestar fundamentada en un justo sistema de protección y promoción social, pensamos que los Servicios Sociales y el Trabajo Social pueden encontrar en las teorías educativas ( también en los modelos y métodos pedagógicos) una fundamentación y consistencia que sería injustificable fueran rechazadas por problemas de dudosa entidad científica , ya que ello afectaría negativamente al ciudadano receptor de estos servicios.

\section{Educación social como paidocenosis}

Convencidos de que los problemas de integración y solidaridad social pasan por un complejo conjunto de estímulos, entre los que podemos considerar al educador, pero en modo alguno reducir a él la responsabilidad educativa de una colectividad, hemos de pensar en la educación social como un conjunto de estímulos (paidocenosis) que posibilitará que una sociedad disponga de un mayor o menor nivel de socialización.

Lo educativo tiene sentido en el seno de un proceso más general , en el que el pueblo se conforma como sujeto popular. Y si es fuera del aula donde se configura la personalidad del individuo no parece incorrecta la posición de aquellos que definen la educación social como una paidocenosis, como una responsabilidad educadora de la sociedad. Como decía Dilthey, la educación es una función de la sociedad.

C. Volpi, el representante italiano más reconocido dentro de esta postura, afirma de manera taxativa que la educación social debe supeditar su acción a los «condicionamientos sociales", Es decir , es condición previa a la intervención socio-educativa el conocimiento de la sociedad, esa sociedad educadora, esa "aula sin muros" que es educada y, a su vez, educa. Nosotros, desde la perspectiva del bienestar y sin renunciar a otras funciones de la educación social, pensamos, como defendían Mollenhauer, Giesecke, Thiersc y otros, que ésta debe entenderse también como un eficaz recurso de mejora de la propia saciedad, como una revisión de la sociedad y de la misma educación social. De ahí que la educación social se pueda concebir como una reflexión crítica de esa sociedad y como un amplio y diverso conjunto de intervenciones cerca de ella, principalmente cerca de aquellos sectores de la sociedad que presentan problemáticas específicas. 
Educación social y educación extraescolar

Además de estos enfoques o concepciones de la educación social, existe una manera excluyente de definir su ámbito de intervención. Consiste en recurrir al impreciso y semánticamente incorrecto concepto de «extra-escolaridad». En este sentido la educación social abarcaría toda intervención educativa estructurada que no fuera estrictamente escolar . Esta concepción, sin ser nueva, ya que fue defendida con gran rigor por Gertrud Baümer, discípula de Nohl, que consideraba la «educación social» como una actividad a desarrollar "fuera de la familia y de la escuela... como tarea educativa social y estatal, en tanto que se realiza fuera de la escuela", está tomando carta de naturaleza en nuestra realidad. (Citado en Quintana, 1988)

A pesar de que esta rígida separación entre los espacios pedagógicos nos parece poco adecuada a la realidad del fenómeno educativo, pensamos que el estudio y la fijación de los objetivos de socialización a través de la acción en el aula es competencia de la pedagogía escolar. En este sentido parece ser que la nueva filosofía defendida por la LOGSE, principalmente a través de los llamados «objetivos transversales», vienen a confirmar nuestra postura. Ahora bien, si la educación social pretende que el individuo sea capaz de comprender su entorno social , político, económico y cultural e integrarse de manera adecuada al mismo, no cabe duda de que se trata de una acción pedagógica intencional y reglada, aunque, como hemos visto, sólo muy incidentalmente escolar.

\section{Educación social y prevención de causas}

Sea cual fuere el enfoque desde el que definamos la educación social, pensamos que ésta debe actuar sobre las «causas» que generan los desajustes sociales. En una sociedad del bienestar, el concepto de educación social no puede referirse a una actividad meramente adaptativa o pasiva. De ahí, pues, que no podamos asimilar educación social a socialización, ni tampoco la educación social a una mera adaptación o normalización social.

Nos parece importante señalar que las nuevas formas del Estado del Bienestar deben facilitar la intervención socio-educativa desde los supuestos de la pedagogía y no desde ciertas estrategias políticas, principalmente cuando éstas no coinciden con los principios o supuestos de una correcta teoría de la prevención de causas. Si el trabajo socio-pedagógico es un movimiento, una actividad que surge de la propia necesidad de la vida en convivencia, la relación entre educación y realidad social parece evidente, como palpable es la relación entre educación social y política siempre que esta relación no implique un innecesario determinismo o intrusismo en los principios pedagógicos.

\section{Hacia un concepto integrador de la educación social}

Una de las consecuencias del Estado del Bienestar ha sido demostrar que el funcionamiento de los sistemas de relación social son fenómenos de tanta complejidad que se hace difícil delimitar en una sola concepción o definición cualquier situación social. De ahí nuestro convencimiento de que el fenómeno de la educación social debe ser abordado desde una perspectiva integradora.

Dado que la educación social está fuertemente comprometida con el conjunto de la vida coridiana del sujeto normalizado, inadaptado y marginado, será competencia suya incidir en favor de una transformación de las actitudes individuales y colectivas de los diferentes sectores de la población. Sólo a partir de una óptica generalizante de la sociedad será factible que la educación social cambie ciertas parcelas de la realidad y pueda, a su vez, generar nuevos espacios de educación social. Porque, 
no lo olvidemos, una de las funciones de la educación social es generar nuevas necesidades sociales, generar nuevas demandas de educación social. Sólo así será posible evitar que de la convivencia comunitaria obtengan mucho más provecho unos que otros, y que ese desequilibrio se produzca precisamente en detrimento de unos y en beneficio de otros.

La educación social debe ser conceptualizada y explicada en función de factores tan diversos como el contexto social, la concepción política, las formas de cultura predominantes, la situación económica y la realidad educativa del momento. De tal manera pensamos que ello es así, que sólo es posible interpretar el actual resurgir de la educación social atendiendo a los significativos cambios que, recientemente, se han dado en nuestro contexto social más inmediato. El advenimiento de la democracia , la construcción y el cierto deterioro del Estado del Bienestar, el incremento del tiempo de ocio, la implantación de una pedagogía del tiempo libre y, principalmente, la conciencia de responsabilidad frente a una sociedad de marginación y anadaptación social, son algunos de los factores explicativos de lo que yo denominaría la «nueva educación social».

\section{REFLEXIONES FINALES}

La dificultad que implica establecer relaciones entre un movimiento como la cultura del bienestar y la educación social son evidentes, ya que se trata de sus realidades sociales muy diferentes y distantes en su génesis y desarrollo. Con todo, si tuviéramos que significar las características de la cultura y el Estado del Bienestar que de manera más decisiva influyeron en el «nacimiento" y desarrollo de la nueva educación social, citaríamos las cinco siguientes:

1. El que la sociedad haya adquirido plena conciencia de los derechos que supone vivir en un Estado Social y de Derecho.

2. La generalización del bienestar como derecho de todos los ciudadanos.

3. La responsabilidad del Estado frente a las necesidades básicas mediante la provisión pública de servicios sociales.

4. El que la sociedad haya alcanzado un determinado desarrollo económico (casi siempre capitalista). Ello posibilita que el Estado asuma compromisos sociales y educativos que van más allá de las necesidades biológicas y escolares.

5. La progresiva intervención del Estado en la política económica y cultural, ya que ello favoreció el desarrollo de la educación social.

6. Mayor intervención del Estado en el diseño y responsabilidad de las política sociales.

Como consecuencia de estas y otras circunstancias, la actual educación social se desenvuelve en un contexto que podríamos considerar como residual del Estado del Bienestar. Fundamentado en la familia y en un eficaz mercado económico como recursos para satisfacer las necesidades sociales, la intervención del Estado se produce cuando aquéllos no son capaces de producir los efectos esperados y el ciudadano queda en situación de cierta indefensión social.

Desde esta perspectiva, el modelo de bienestar social ofertado por los poderes públicos se dirige a minorías residuales y la educación social adquiere un cierto carácter reparador. Interviene cuando las necesidades se han producido y no, como sería de desear, antes de que aquéllas aparezcan y como una prestación a la totalidad de la población.

Ante esta situación, las políticas sociales pensaron en la necesidad de redefinir el sujeto de la educación social. Se trataba de superar el signo estigmatizador de la prestación y la educación social y de universalizar sus campos de acción. Dejar las capas empobrecidas como único referente de su intervención y dirigirse a todos los 
sectores de la población es un reto que poco a poco va asumiéndose, al menos conceptualmente.

Ahora bien, una intervención desvinculada de las carencias, una educación social para todos comporta, no obstante, una fuerte inversión económica pública que no siempre el Estado puede asumir. Y cuando esto sucede, el modelo de Estado del Bienestar institucional deja más indefensos, si cabe, a los sectores menos privilegiados y más débiles frente a la crisis.

Ante esta situación, cabe hacerse una consideración final. ¿Optamos por un modelo de bienestar o dirigimos nuestra acción a solucionar los problemas de los marginados?

\section{Notas}

(1) Aunque hayamos afirmado que los tres partidos políticos con más presencia en la europea de los año 1950-70 consensuaron sus teorías respecto al Estado del bienestar, lo cierto es que entre los planteamientos defendido por uno y otro partido median ciertas diferencias que es preciso tener presente a la hora de estudiar las relaciones entre la cultura del bienestar y la educación social. (Pico, 1987)

(2) Autores como Titmus, Crossland y Marshall representarían la tendencia socialdemócrata más pragmática, mientras que un autor tan reconocido como Bobbio sería el exponente de aquellos que más cercanos a un cierto marxismo no acepran, sin embargo, que todo análisis del cambio social tenga que pasar forzosamente por las relaciones de producción. (AA.VV., 1986; Habermas, 1976)

(3) Juan Maro, Director General de Protección Juridica del Menor, en un artículo titulado «Situación actual y futuro del educador social» $(1991,27)$, dice que la educación social «es un elemento clave en el proceso de socialización", ya que el progresivo proceso de individualización y las consiguientes rupturas de la dinámica social, generan unos importantes espacios de acción profesional socio-educativa. (AAVV, 1991)

(4) Lowy ha realizado una interesante síntesis de las concepciones y diferencias existentes entre el trabajo social y la educación social en el ámbito de los países anglosajones. (Aristu,1991)

(5) Ortega y Gasset concibe la educación social desde una doble función: como la estrategia que permite la inserción del ciudadano en su sociedad o comunidad, y como un programa político capaz de transformar a la sociedad. (Ortega y Gasset, 1968)

\section{Referencias}

AA.VV. (1986). Politica social de las Comunidades Europeas. Madrid: ACEBO.

AA.VV. (1991). El Educador Social. Presente y Futuro. Bilbao: Asociación de Educadores Especializados. Alvarez CONDE, E. (1985). El régimen político español. Madrid: Tecnos.

ARISTU, J (1991). Acción comunicativa e intervención social. Madrid: Editorial Popular.

COMision de las COMUNIDADES EuROPEAS (1993): Libro verde. Política Social Europea. Dirección General de Empleo, Relaciones Industriales y Asuntos Sociales.

GARRIDO GENOVEs, V. y otros (1989). El tratamiento de delincuentes institucionalizados: El programa de competencia psicosocial en la prisión de jóvenes la Trinidad de Barcelona. DelincuencialDelinquency, 1 (1), 37-5

HABERMAS, J. (1976). Conservatism and capistalist crisis. Londres: NLR.

LÓPEZ Hidalgo, J. (1992). Los Servicios Sociales (Aproximación conceptual a los indicadores discriminatorios). Madrid: Narcea .

MuÑoz DE BustrLlo, R. (Comp.) (1989). Crisis y futuro del Estado de bienestar. Madrid: Alianza.

OFFE, C. (1994) . Contradicciones en el Estado del Bienestar. Madrid: Alianza Universidad.

ORTEGA Y GASSET, J. La Pedagogía Social como programa político. Obras Completas, Tomo I (1968) Madrid: Revista de Occidente.

Petrus Rotger, A. (1988). Control y Pedagogía Social. Poder y Control, Revista hispanoamericana de disciplinas sobre el control social. Barcelona: Promociones Publicaciones Universitarias.

PICO, J. (1987). Teorias sobre el Estado de l Bienestar. Madrid: Siglo XXI.

Quintana, J. M. (1988). Pedagogia Social. Madrid: Dykinson.

ZAPATERO, V. ( 1989). Tres visiones sobre el Estado del Bienestar. Revista Sistema, 80-81. 


\section{La educación social en la cultura del bienestar Antoni Petrus \\ CL\&E, 1995, 27, pp. 5-20}

Resumen: En el artículo, centrado en la educación social y el estado del bienestar, se analizan los modelos en que actualmente se relaciona la educación social con las formas del Estado de Bienestar: modelo liberal-democrata, modelo social-democrata y modelo neocorporativista y se presentan los principales enfoques que de la educación social se perciben en la cultura del bienestar: educación social como socialización, como acción social cualificada, como factor de intervención educativa cerca de la inadaptación social, como adquisición de competencias sociales, como didáctica social, como formación política del ciudadano, como prevención y control social, como trabajo social educativo y como paidocenosis.

Datos sobre el autor: Antonio Petrus Rotger es Caredrático de Pedagogia Social de la Universidad de Barcelona. Ha escrito distintos artículos relacionados con el tema de la educación social.

Dirección: Departamento de Teoría e Historia de la Educación, Facultad de Pedagogía, Universidad de Barcelona, Baldiri Reixac, s/n. 08028 Barcelona. Tel (93) 4409200.

(C) PERMISOS PARA CITAR O REPRODUCIR EN OTRAS FUENTES: Se pueden citar libremente hasta 500 palabras. Para reproducir una porción de texto mayor, figuras o ilustraciones, se deberá pedir permiso por escrito a la revista, especificando el uso al que se destina el texto. En todos los casos, se deberá citar el copyright de $C L \& E$. En el caso de artículos o textos que hayan sido a su vez reproducidos en $C L \& E$ los interesados deberán dirigirse tanto a los detentadores del copyright original como a $C L \& E$, en el caso de que se quiera hacer uso de la traducción. FOTOCOPIAS: Para todo lo relacionado con el uso mediante fotocopia del material de esta revista, deberán dirigirse a: CEDRO, C/ José Marañón, 10, 3. ${ }^{\circ}$ Izda. Tel. 5941575 . Fax 4453567 